\title{
Synthesis and Characterization of Novel Conjugated Polymer with $4 H$-Cyclopenta[def]phenanthrene and the Sulfanyl Group
}

\author{
By Suhee SONG, ${ }^{1}$ Youngeup JIN, ${ }^{1, *}$ Sun Hee KIM, ${ }^{2}$ \\ Joo Hyun KIM, ${ }^{3}$ Kwanghee LEE, ${ }^{2}$ and Hongsuk SUH ${ }^{1, *}$
}

A novel $4 H$-cyclopenta[ $[$ ef] phenanthrene (CPP) derivative with bis-methylsulfanyl-methylene unit was synthesized from $\mathrm{CPP}, \mathrm{CH}_{3} \mathrm{I}$, and $\mathrm{CS}_{2}$. The structure and absolute configuration was determined on the basis of spectroscopic analyses and $\mathrm{X}$-ray diffraction. New electroluminescent polymer with bis-methylsulfanyl-methylene unit in the PCPP backbone, poly((2,6-(4,4-bis(2-ethylhexyl)-4H-cyclopenta[def]phenanthrene))-alt-(2,6-(4-(bis(methylsulfanyl)methylene)- $4 H$-cyclopenta[def]phenanthrene))) (PCPP-MSC), have been synthesized by the Suzuki coupling reaction. The bis-methylsulfanyl-methylene unit was introduced on the PCPP backbone to affect a red-shifted color change and to increase the electron affinities of the polymer. The HOMO energy level of the polymer was $-5.65 \mathrm{eV}$, and the LUMO energy level was $-2.92 \mathrm{eV}$. The polymer, PCPP-MSC, using this CPP derivative exhibited absorption spectra with maximum peak at $341 \mathrm{~nm}$ in chlorobenzene solution and at $344 \mathrm{~nm}$ in the solid film state. The PCPP-MSC showed two PL emission peaks at 404 and $522 \mathrm{~nm}$ in chloroform solution with changing concentration. As concentration was growing from $1 \times 10^{-8} \mathrm{~mol} / \mathrm{L}$ to $1 \times 10^{-5} \mathrm{~mol} / \mathrm{L}$, the PL peak at $522 \mathrm{~nm}$ increased dramatically, and the complete quenching of the host emission at $404 \mathrm{~nm}$ was observed, since complete aggregation between the cyclopentaphenanthrene segment and the methylsulfanylmethylene unit was induced by an intermolecular interaction.

KEY WORDS: Conjugated Polymer / 4H-cyclopenta[def]phenanthrene / Intermolecular Interaction / Optical Properties /

In the past few years, much research has been devoted to polymer light-emitting diodes (PLEDs) through the design and synthesis of light-emitting polymers for practical applications. ${ }^{1}$ The color control and tuning of optical properties of conjugated polymers are important subject to achieve electroluminescence (EL) devices composed of these luminescent polymer materials. There are a few appropriate polymers for fabricating PLEDs that emit blue, ${ }^{2}$ green, ${ }^{3}$ and red colors. ${ }^{4}$ Recently, redemitting materials have been reported from the energy transfer between emissive polymers and several dyes, such as tetraphenylporphyrin and europium complexes. ${ }^{5}$ In this reason, the relation between the material structure was more important topic of discussion.

To design polymers with improved functional properties that cannot easily be attained by the corresponding homopolymers, considerable attention has been given to the syntheses and properties of conjugated copolymers in which the characteristics of the co-monomers possess a novel means. ${ }^{6}$ One of the keys in improvement of PLEDs is the discovery of the guesthost doped emitter system. ${ }^{7}$ A wide-band-gap host, with optimized transport and luminescent properties such as PFs, and a variety of highly fluorescent or phosphorescent narrowband-gap guest dopants have been used to generate EL of desirable colors with very high efficiencies. New conjugated units containing sulfur, like 2,1,3-benzothiadiazole (BTs), ${ }^{8}$ have been investigated for use in red-light-emitting diodes.
Caused by the relatively high reduction potential and electron affinity, BTs are one of the most important moieties among the narrow-band-gap co-monomers. However, many light-emitting polymers with low electron affinities inject and transport holes due to their abundance of $\pi$-electrons. ${ }^{9}$ The strong electrondonor ability of these conjugated backbones have led to their application as a component of inter- and intramolecular chargetransfer systems. ${ }^{10}$ There are some reports about copolymers based on fluorene as a donor with various acceptor including BT. On the other hand, the monomer 4-(bis-methylsulfanylmethylene)-4H-cyclopenta[def]phenanthrene (MSC) bearing only one bis-methylsulfanyl unit, ${ }^{11}$ has received much less attention.

We have recently reported the synthesis of polycyclopentaphenanthrene (PCPP), ${ }^{12}$ a new conjugated polymer previously investigated as a prospective blue emitting layer for PLEDs, given the stability of its thin film without any low-energy emission bands in the region of $500-600 \mathrm{~nm}$ even after annealing in air for $18 \mathrm{~h}$ at $150^{\circ} \mathrm{C}$ or operation of the device in air for $40 \mathrm{~min}$. The PLED based on PCPP generates EL emissions with high maximum brightness $\left(1500 \mathrm{~cd} / \mathrm{m}^{2}\right.$ at $14 \mathrm{~V})$, high efficiency $\left(0.70 \mathrm{~cd} / \mathrm{A}\right.$ at $\left.180 \mathrm{~mA} / \mathrm{cm}^{2}\right)$, maximum peak at $400 \mathrm{~nm}$, low turn-on voltage $(6.0 \mathrm{~V})$ and excellent CIE coordinates $(\mathrm{x}=0.17, \mathrm{y}=0.12)$ for the blue color without any filtering. Emission color of PCPP can be changed over an entire visible region by introducing narrow-band-gap co-monomers

\footnotetext{
${ }^{1}$ Department of Chemistry and Chemistry Institute for Functional Materials, Pusan National University, Busan 609-735, Korea

${ }^{2}$ Department of Materials Science and Engineering, Gwangju Institute of Science and Technology, Gwangju 500-712, Korea

${ }^{3}$ Division of Applied Chemical Engineering, Pukyong National University, Busan 608-739, Korea

*To whom correspondence should be addressed (Tel: +82-51-510-2203, Fax: +82-51-516-7421, E-mail: hssuh@ pusan.ac.kr (Hongsuk Suh), Tel: +8251-510-3238, Fax: +82-51-516-7421, E-mail: yej@pusan.ac.kr (Youngeup Jin)).
} 
into the PCPP backbone. In this work, we report on the synthesis, by Suzuki coupling, and characterization of the copolymer of $4 H$-cyclopenta[def]phenanthrene (CPP) and MSC. The MSC units were introduced into the main chains of PCPP for color tuning. The maximum peak of the PL spectra was at 545 and $649 \mathrm{~nm}$. Devices based on this copolymer can emit red light with an emission maximum at $661 \mathrm{~nm}$.

\section{EXPERIMENTAL}

\section{Materials and Instruments}

All reagents were purchased from Aldrich or TCI, and used without further purification. Solvents were purified by normal procedure and handled under moisture-free atmosphere. ${ }^{1} \mathrm{H}$ and ${ }^{13} \mathrm{C}$ NMR spectra were recorded with a Varian Gemini-300 $(300 \mathrm{MHz})$ spectrometer and chemical shifts were recorded in ppm units with TMS as the internal standard. Flash column chromatography was performed with Merck silica gel 60 (particle size 230-400 mesh ASTM) with ethyl acetate/hexane or methanol/methylene chloride gradients unless otherwise indicated. Analytical thin layer chromatography (TLC) was conducted using Merck $0.25 \mathrm{~mm}$ silica gel $60 \mathrm{~F}$ pre-coated aluminum plates with fluorescent indicator UV254. High resolution mass spectra (HRMS) were recorded on a JEOL JMS-700 mass spectrometer under electron impact (EI) or fast atom bombardment (FAB) conditions in the Korea Basic Science Institute (Daegu, Korea). Elemental analyses (EA) were performed by Flash EA 1112 Series. Molecular weight and polydispersity of the polymer were determined by gel permeation chromatography (GPC) analysis with a polystyrene standard calibration. The thermal propertied of this polymer was characterized by both differential scanning calorimetry (DSC) and thermal gravimetric analysis (TGA). $T_{\mathrm{g}}$ is temperature of transition of an amorphous or semi-crystalline polymer from a rubbery state to a glassy state. $T_{\mathrm{d}}$ is temperature at $5 \mathrm{wt} \%$ loss under nitrogen atmosphere. The differential scanning calorimetry (DSC) analysis was performed under a nitrogen atmosphere $(50 \mathrm{~mL} / \mathrm{min})$ on a DSC 822 at heating rates of $10^{\circ} \mathrm{C} / \mathrm{min}$. Thermogravimetric analysis (TGA) was performed with a Dupont 951 TGA instrument in a nitrogen atmosphere at a heating rate of $10^{\circ} \mathrm{C} / \mathrm{min}$ to $800^{\circ} \mathrm{C}$. Cyclic voltammetric waves were produced by using a EG\&G Parc model 273 potentiostat/galvanostat at a constant scan rate of $100 \mathrm{mV} / \mathrm{s}$.

\section{Device Fabrication and Measurements}

The UV-vis absorption spectra were recorded by a Varian Cary 1 spectrophotometer, while the Oriel InstaSpec IV CCD detection system with halogen lamp was used for the photoluminescence and electroluminescence spectra measurements. For the EL experiment, poly(3,4-ethylenedioxythiophene) (PEDOT) doped with poly(styrenesulfonate) (PSS), as the hole-injection-transport layer, was introduced between emissive layer and ITO glass substrate cleaned by successive ultrasonic treatments. The solution of the PEDOT:PSS in aqueous isopropyl alcohol was spin-coated on the surface- treated ITO substrate and dried on a hot plate for $30 \mathrm{~min}$ at $110^{\circ} \mathrm{C}$. On top of the PEDOT:PSS layer, the emissive polymer film was obtained by spin casting chlorobenzene solution of the polymer. The emissive polymer thin film prepared had a uniform surface with a thickness of around $110 \mathrm{~nm}$. The emissive film was dried in vacuum, and Calcium electrodes were deposited on the top of the polymer films through a mask by vacuum evaporation at pressures below $10^{-7}$ Torr, yielding active areas of $4 \mathrm{~mm}^{2}$. For the determination of device characteristics, Current density-voltage $(J-V)$ and luminancevoltage $(L-V)$ characteristics of the devices were measured using a Keithley 2400 Source Measure Unit equipped with a calibrated photomultiplier tube.

\section{Synthesis of Monomers and Polymer}

8,9-Dihydro-4H-cyclopenta[def]phenanthrene (2). The mixture of $4 H$-cyclopenta[def]phenanthrene (1) (1.45 g, 7.62 $\mathrm{mmol}), 10 \%$ palladium-charcoal $(300 \mathrm{mg})$, and methanol/ dichloromethane $(40 \mathrm{~mL} / 40 \mathrm{~mL})$ was shaken for $15 \mathrm{~h}$ at room temperature under a hydrogen atmosphere $(60 \mathrm{psi})$. After removal of the catalyst by filtration, the solvent was evaporated under reduced pressure. The residue was purified by flash column chromatography to give $1.46 \mathrm{~g}$ (100\%) of compound 2 as white solid: $\mathrm{mp} 134{ }^{\circ} \mathrm{C} ; R_{\mathrm{f}} 0.44\left(\mathrm{SiO}_{2}, 100 \%\right.$ hexane $)$ ${ }^{1} \mathrm{H}$ NMR $\left(300 \mathrm{MHz}, \mathrm{CDCl}_{3}\right): \delta(\mathrm{ppm}) 3.18(\mathrm{~s}, 4 \mathrm{H}), 3.92(\mathrm{~s}$, $2 \mathrm{H}), 7.17(\mathrm{~d}, 2 \mathrm{H}, J=7.4 \mathrm{~Hz}), 7.24(\mathrm{t}, 2 \mathrm{H}, J=7.4 \mathrm{~Hz}), 7.37(\mathrm{~d}$, $2 \mathrm{H}, J=7.4 \mathrm{~Hz}) ;{ }^{13} \mathrm{C} \mathrm{NMR}\left(75 \mathrm{MHz}, \mathrm{CDCl}_{3}\right): \delta(\mathrm{ppm}) 26.51$, $37.69,122.95,124.92,127.51,130.76,139.65,140.67$. HRMS $\left(\mathrm{m} / \mathrm{z}, \mathrm{EI}^{+}\right)$calcd for $\mathrm{C}_{15} \mathrm{H}_{12}$ 192.0939, found 192.0943.

2,6-Dibromo-8,9-dihydro-4H-cyclopenta[def]phenanthrene (3). To prepare copper bromide adsorbed on alumina, a solution of $10 \mathrm{~g}$ of copper bromide in $30 \mathrm{~mL}$ of distilled water was treated with neutral alumina ( $20 \mathrm{~g}$, Merck aluminum oxide 90 active neutral) at room temperature. The reaction mixture was concentrated at $80^{\circ} \mathrm{C}$ under reduced pressure. The resulting residue was dried under vacuum (4 Torr) at $100{ }^{\circ} \mathrm{C}$ for $15 \mathrm{~h}$ to generate the copper bromide adsorbed on alumina. To a stirred solution of $1.87 \mathrm{~g}(3.59 \mathrm{mmol})$ of 8,9 -dihydro- $4 \mathrm{H}$ cyclopenta[def]phenanthrene (2) in $70 \mathrm{~mL}$ of carbon tetrachloride at room temperature was added $31.6 \mathrm{~g}$ of copper bromide adsorbed on alumina. After $5 \mathrm{~h}$ at $60^{\circ} \mathrm{C}$, the solid was filtered and washed with $2 \times 30 \mathrm{~mL}$ of carbon tetrachloride. The combined organic phase was concentrated under reduced pressure and purified by flash column chromatography to give $3.36 \mathrm{~g}(99 \%)$ of compound $\mathbf{3}$ as pale yellow solid: $\mathrm{mp} 184^{\circ} \mathrm{C}$; $R_{\mathrm{f}} 0.50\left(\mathrm{SiO}_{2}, 100 \%\right.$ hexane). ${ }^{1} \mathrm{H} \mathrm{NMR}\left(300 \mathrm{MHz}, \mathrm{CDCl}_{3}\right): \delta$ (ppm) 3.08 (s, 4H), 3.83 (s, 2H), 7.46 (s, 2H), 7.47 (s, 2H); ${ }^{13} \mathrm{C} \mathrm{NMR}\left(75 \mathrm{MHz}, \mathrm{CDCl}_{3}\right): \delta$ (ppm) 25.95, 37.35, 121.33, $126.43,128.43,131.91,137.56,141.81 . \operatorname{HRMS}\left(m / z, \mathrm{EI}^{+}\right)$ calcd for $\mathrm{C}_{15} \mathrm{H}_{10} \mathrm{Br}_{2}$ 347.9149, found 347.9153.

2,6-Dibromo-4H-cyclopenta[def]phenanthrene (4). To a stirred solution of $3.15 \mathrm{~g}(9.1 \mathrm{mmol})$ of 2,6-dibromo-8,9-dihydro$4 H$-cyclopenta[def]phenanthrene $(3)$ in $70 \mathrm{~mL}$ of carbon disulfide at room temperature was added dropwise $0.56 \mathrm{~mL}(10.8$ $\mathrm{mmol}$ ) of $\mathrm{Br}_{2}$ in carbon disulfide over $3 \mathrm{~h}$. The reaction mixture was stirred for $1 \mathrm{~h}$, concentrated under reduced pressure, and 


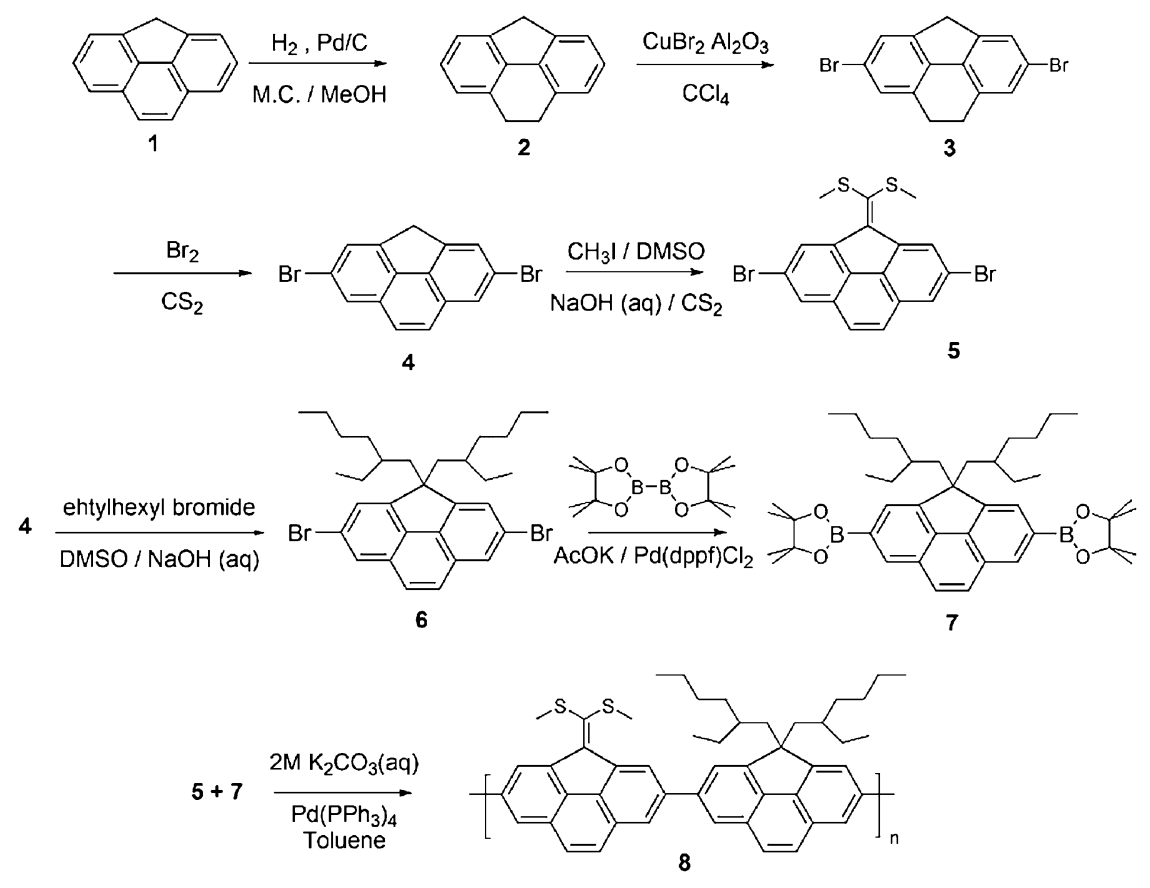

Scheme 1. Synthetic routes for PCPP-MSC.

purified by flash column chromatography to give $3.15 \mathrm{~g}$ (100\%) of compound 4 as pale yellow solid: $\mathrm{mp} 210^{\circ} \mathrm{C} ; R_{\mathrm{f}} 0.53\left(\mathrm{SiO}_{2}\right.$, $100 \%$ hexane). ${ }^{1} \mathrm{H}$ NMR $\left(300 \mathrm{MHz}, \mathrm{CDCl}_{3}\right): \delta(\mathrm{ppm}) 4.32(\mathrm{~s}$, $2 \mathrm{H}), 7.75$ (s, 2H), $7.80(\mathrm{~s}, 2 \mathrm{H}), 7.99(\mathrm{~s}, 2 \mathrm{H}) ;{ }^{13} \mathrm{C} \mathrm{NMR}$ $\left(75 \mathrm{MHz}, \mathrm{CDCl}_{3}\right): \delta(\mathrm{ppm}) 37.16,125.31,125.62,126.41$, 127.97, 128.97, 132.91, 143.03. HRMS $\left(\mathrm{m} / \mathrm{z}, \mathrm{EI}^{+}\right)$calcd for $\mathrm{C}_{15} \mathrm{H}_{8} \mathrm{Br}_{2}$ 345.8993, found 345.8993. Anal. Calcd for $\mathrm{C}_{15} \mathrm{H}_{10} \mathrm{Br}_{2}$ : C, 51.77; H, 2.32. Found: C, 52.60; H, 1.85 .

4-(Bis(methylsulfanyl)methylene)-2,6-dibromo-4H-cyclopenta[def]phenanthrene (5). To a stirred solution of $9.16 \mathrm{~g}$ (26.3 mmol) of 2,6-dibromo- $4 H$-cyclopenta[def]phenanthrene (4) and catalytic amounts of triethylbenzylammonium chloride in $500 \mathrm{~mL}$ of DMSO and $100 \mathrm{~mL}$ of $\mathrm{CS}_{2}$ under nitrogen was added $9.8 \mathrm{~mL}(157.9 \mathrm{mmol})$ of iodomethane. After $1 \mathrm{~h}$ at $60^{\circ} \mathrm{C}$, $10 \mathrm{~mL}$ of $50 \%$ aqueous $\mathrm{NaOH}$ solution was added. The reaction mixture was cooled to room temperature and stirred for $5 \mathrm{~h}$. After an excess amount of ethyl acetate was added, the organic layer was washed with $3 \times 500 \mathrm{~mL}$ of water. The organic phase was dried with $\mathrm{MgSO}_{4}$ and concentrated under reduced pressure. The residue was purified by flash column chromatography to give $2.82 \mathrm{~g}(19.5 \%)$ of compound $\mathbf{5}$, yellow powder: mp $191{ }^{\circ} \mathrm{C} ; R_{\mathrm{f}} 0.45\left(\mathrm{SiO}_{2}\right.$, methylene choride:hexane $=1: 10) .{ }^{1} \mathrm{H} \mathrm{NMR}\left(300 \mathrm{MHz}, \mathrm{CDCl}_{3}\right): \delta(\mathrm{ppm}) 1.82(\mathrm{~s}$, $6 \mathrm{H}), 7.27(\mathrm{~s}, 2 \mathrm{H}), 7.95(\mathrm{~s}, 2 \mathrm{H}), 8.82(\mathrm{~s}, 2 \mathrm{H}) ;{ }^{13} \mathrm{C} \mathrm{NMR}$ $\left(75 \mathrm{MHz}, \mathrm{CDCl}_{3}\right): \delta(\mathrm{ppm}) 18.25,23.85,121.87,125.08$, $126.42,127.53,127.94,133.40,136.54,138.30$. HRMS $(m / z$, $\mathrm{EI}^{+}$) calcd for $\mathrm{C}_{18} \mathrm{H}_{12} \mathrm{Br}_{2} \mathrm{~S}_{2}$ 449.8747, found 449.8748. Anal. Calcd for $\mathrm{C}_{18} \mathrm{H}_{12} \mathrm{Br}_{2} \mathrm{~S}_{2}$ : C, 47.81; H, 2.67; S, 14.18. Found: C, 46.93; H, 2.54; S, 16.33.

2,6-Dibromo-4,4-bis(2-ethylhexyl)-4H-cyclopenta[def]phenanthrene (6). To a stirred solution of $3.12 \mathrm{~g}(8.9 \mathrm{mmol})$ of 2,6-dibromo-4H-cyclopenta[def]phenanthrene (4) and catalytic amounts of triethylbenzylammonium chloride in $175 \mathrm{~mL}$ of DMSO under nitrogen was added $4.79 \mathrm{~mL}(27.0 \mathrm{mmol})$ of 2ethylhexylbromide. After $1 \mathrm{~h}$ at $60^{\circ} \mathrm{C}, 10 \mathrm{~mL}$ of $50 \%$ aqueous $\mathrm{NaOH}$ solution was added. The reaction mixture was cooled to room temperature and stirred for $5 \mathrm{~h}$. After an excess amount of ethyl acetate was added to the reaction mixture, the organic layer was washed with $4 \times 100 \mathrm{~mL}$ of water. The organic phase was dried with $\mathrm{MgSO}_{4}$ and concentrated under reduced pressure. The residue was purified by flash column chromatography to give $3.59 \mathrm{~g}(69.8 \%)$ of extremely clean compound 6, white solid: $\mathrm{mp} 44{ }^{\circ} \mathrm{C} ; R_{\mathrm{f}} 0.65\left(\mathrm{SiO}_{2}, 100 \%\right.$ hexane $)$. ${ }^{1} \mathrm{H}$ NMR $\left(300 \mathrm{MHz}, \mathrm{CDCl}_{3}\right): \delta(\mathrm{ppm})$ 0.49-0.85 (m, 30H), $2.12(\mathrm{~m}, 4 \mathrm{H}), 7.66(\mathrm{t}, 2 \mathrm{H}, J=1.1 \mathrm{~Hz}), 7.76(\mathrm{~s}, 2 \mathrm{H}), 7.97(\mathrm{~d}$, $2 \mathrm{H}, J=1.1 \mathrm{~Hz}) ;{ }^{13} \mathrm{C} \mathrm{NMR}\left(75 \mathrm{MHz}, \mathrm{CDCl}_{3}\right): \delta(\mathrm{ppm}) 10.54$, 14.20, 22.86, 27.55, 28.30, 34.08, 35.46, 44.04, 59.72, 121.86, $124.69,125.63,125.90,128.64,135.44,150.96$. HRMS $(m / z$, $\mathrm{EI}^{+}$) calcd for $\mathrm{C}_{31} \mathrm{H}_{40} \mathrm{Br}_{2}$ 570.1497, found 570.1532. Anal. Calcd for $\mathrm{C}_{31} \mathrm{H}_{40} \mathrm{Br}_{2}$ : C, 65.04; H, 7.04. Found: C, 64.67; H, 7.41 .

2-[4,4-Bis(2-ethylhexyl)-6-(4,4,5,5-tetramethyl-1,3,2-dioxaborolan-2-yl)-4H-cyclopenta [def]phenanthren-2-yl]-4,4,5,5-tetramethyl-1,3,2-dioxaborolane (7). Under an argon atmosphere, 2,6-dibromo-4,4-bis(2-ethylhexyl)-4H-cyclopenta[def]phenanthrene (6) (2.19g, $3.8 \mathrm{mmol})$, bis(pinacolato)diboron $(4.86 \mathrm{~g}$, $19.2 \mathrm{mmol}), \mathrm{AcOK}(2.26 \mathrm{~g}, 22.9 \mathrm{mmol})$, and $\mathrm{Pd}(\mathrm{dppf}) \mathrm{Cl}_{2}$ $(0.18 \mathrm{~g}, 0.23 \mathrm{mmol})$ were dissolved in DMF $(40 \mathrm{~mL})$ and heated to $60{ }^{\circ} \mathrm{C}$ overnight. After the reaction mixture was cooled to room temperature, water and diethyl ether were added. The aqueous phase was extracted with diethyl ether and combined organic layer were dried over $\mathrm{MgSO}_{4}$. The solvent was removed under vacuum and the residue was purified by column chromatography to give $2.0 \mathrm{~g}(78 \%)$ of compound 7 , as 
white solid: $\mathrm{mp} 97^{\circ} \mathrm{C} ; R_{\mathrm{f}} 0.42\left(\mathrm{SiO}_{2}\right.$, ethyl acetate:hexane $=$ 1:14). ${ }^{1} \mathrm{H}$ NMR $\left(300 \mathrm{MHz}, \mathrm{CDCl}_{3}\right): \delta$ (ppm) 0.44-0.82 (m, $30 \mathrm{H}), 1.41(\mathrm{~s}, 24 \mathrm{H}), 2.16(\mathrm{~d}, 4 \mathrm{H}, J=4.67 \mathrm{~Hz}), 7.94(\mathrm{~s}, 1 \mathrm{H}$ by chirality of $2 \mathrm{H}), 7.96$ (s, $2 \mathrm{H}$ by chirality of $2 \mathrm{H}), 7.98$ (s, $1 \mathrm{H}$ by chirality of $2 \mathrm{H}), 8.31(\mathrm{~s}, 2 \mathrm{H}) ;{ }^{13} \mathrm{C} \mathrm{NMR}(75 \mathrm{MHz}, \mathrm{CDCl} 3) \delta$ (ppm): 10.61, 14.27, 22.90, 25.14, 27.73, 28.18, 33.98, 35.41, 44.03, 59.04, 83.91, 125.71, 126.04, 127.91, 128.23, 130.79, 139.71, 149.19. HRMS $\left(m / z, \mathrm{FAB}^{+}\right)$calcd for $\mathrm{C}_{43} \mathrm{H}_{64} \mathrm{~B}_{2} \mathrm{O}_{4}$ 666.5005 , found 666.4996 .

Poly((2,6-(4,4-bis(2-ethylhexyl)-4H-cyclopenta[def]phenanthrene))-alt-(2,6-(4-(bis(methylsulfanyl)methylene)-4H-cyclopenta[def]phenanthrene))) (PCPP-MSC) (8). Carefully purified 2-[4,4-bis(2-ethylhexyl)-6-(4,4,5,5-tetramethyl-1,3,2-dioxaborolan-2-yl)-4H-cyclopenta[def]phenanthren-2-yl]-4,4,5,5tetramethyl-1,3,2-dioxaborolane (7) $(544 \mathrm{mg}, 0.8 \mathrm{mmol})$, 4(bis(methylsulfanyl)methylene)-2,6-dibromo-4H-cyclopenta[def]phenanthrene (5) $(369.7 \mathrm{mg}, 0.8 \mathrm{mmol})$, and $\mathrm{Pd}\left(\mathrm{PPh}_{3}\right)_{4}$ (28.3 mg, $0.02 \mathrm{mmol}$ ) were dissolved in a mixture of toluene and aqueous $2 \mathrm{M} \mathrm{K}_{2} \mathrm{CO}_{3}$. The mixture was refluxed with vigorous stirring for $3 \mathrm{~d}$ under argon atmosphere. After the mixture was cooled to room temperature, it was poured into methanol. The precipitated material was recovered by filtration through a funnel. The resulting solid material was reprecipitated using methanol several times to remove catalyst residues. The obtained pale greenish-yellow solid was dried in vacuum to give $0.2 \mathrm{~g}$ : ${ }^{1} \mathrm{H} \mathrm{NMR}(300 \mathrm{MHz}$, $\left.\mathrm{CDCl}_{3}\right): \delta(\mathrm{ppm})$ 0.80-0.87 (m, 26H), $1.61(\mathrm{~s}, 6 \mathrm{H}), 2.11-2.21$ $(\mathrm{m}, 4 \mathrm{H}), 2.44-2.76(\mathrm{~m}, 4 \mathrm{H}), 7.32-8.22(\mathrm{~m}, 10 \mathrm{H}), 9.18(\mathrm{~s}$, $2 \mathrm{H})$. Anal. Calcd for $\mathrm{C}_{49} \mathrm{H}_{52} \mathrm{~S}_{2}$ : C, 83.47; H, 7.43; S, 9.10. Found: C, 81.87; H, 6.60; S, 9.18.

\section{RESULTS AND DISCUSSION}

\section{Synthesis and Characterizations}

The general synthetic routes toward the monomers and polymers are outlined in Scheme 1. In the first step, $4 H$ cyclopenta[def]phenanthrene (1) was hydrogenated using $\mathrm{Pd} / \mathrm{C}$ to generate 8,9 -dihydro-4H-cyclopenta[def]phenanthrene (2). ${ }^{13}$ Alumina-supported copper (II) bromide ${ }^{14}$ was used for the bromination to provide 2,6-bibromo-8,9-dihydro-4H-cyclopenta[def]phenanthrene (3). 2,6-Dibromo-4H-cyclopenta[def]phenanthrene (4) was synthesized by dehydrogenation of compound 3 using bromine and carbon disulfide. After further alkylation of compound $\mathbf{4}$ with methyl iodide, the reaction, upon treatment with $\mathrm{CS}_{2}$ in DMSO and $50 \%$ aqueous $\mathrm{NaOH}$, led to compound $\mathbf{5},{ }^{15}$ then analyzed using HRMS and NMR (500 MHz), including COSY, HMQC, and HMBC, as shown in Figure 1. In addition, the structure of a single crystal of compound 5, obtained from a $\mathrm{CHCl}_{3} /$ hexane solution, was confirmed by X-ray diffraction, as shown in Figure 2. Crystals of compound $\mathbf{5}$ belong to the triclinic system, space group P-1; $a=11.1829$ (8), $b=11.5384$ (8), $c=14.5606$ (10), $\alpha=109.7^{\circ}, \beta=103.3^{\circ}, \gamma=104.4^{\circ}$, Volume $=1609.04$ (19) $\AA, \mathrm{Z}=4, \mathrm{D}_{\text {calcd }}=1.867 \mathrm{Mg} / \mathrm{m}^{3}, m=5.290 \mathrm{~mm}^{-1}, F(000)=$ 888. The final value of $R[\mathrm{I}>2 \sigma(\mathrm{I})]$ was $0.0306, w \mathrm{R}_{2}=$ 0.0782 , GooF $=1.062$. Another monomer, 2-[4,4-bis(2-ethyl-
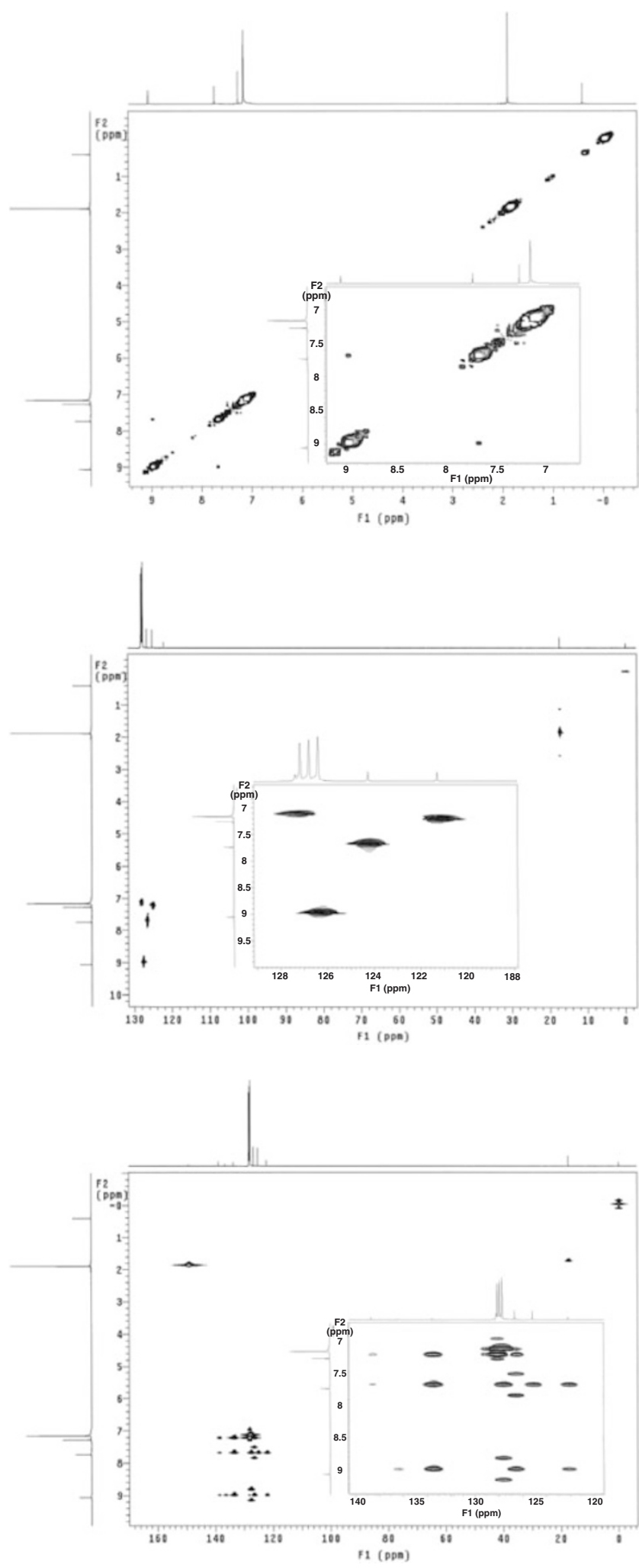

Figure 1. ${ }^{1} \mathrm{H}-{ }^{1} \mathrm{H}$ COSY, $\mathrm{HMQC}$, and $\mathrm{HMBC}$ of compound 5.

hexyl)-6-(4,4,5,5-tetra-methyl-1,3,2-dioxaborolan-2-yl)-4H-cyclopenta[def]phenan-thren-2-yl]-4,4,5,5-tetramethyl-1,3,2-dioxaborolane (7) was synthesized by reacting compound 4 with 2ethylhexylbromide, using catalytic amounts of triethylbenzyl 

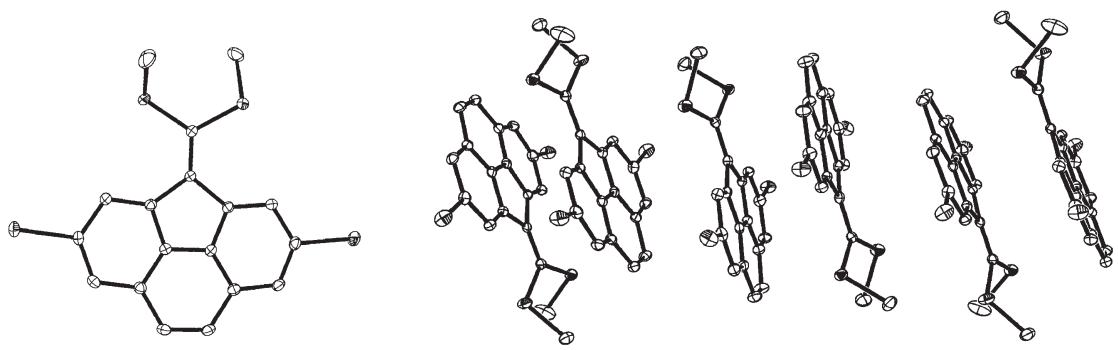

Figure 2. X-Ray structure and packing diagram of compound $\mathbf{5}$
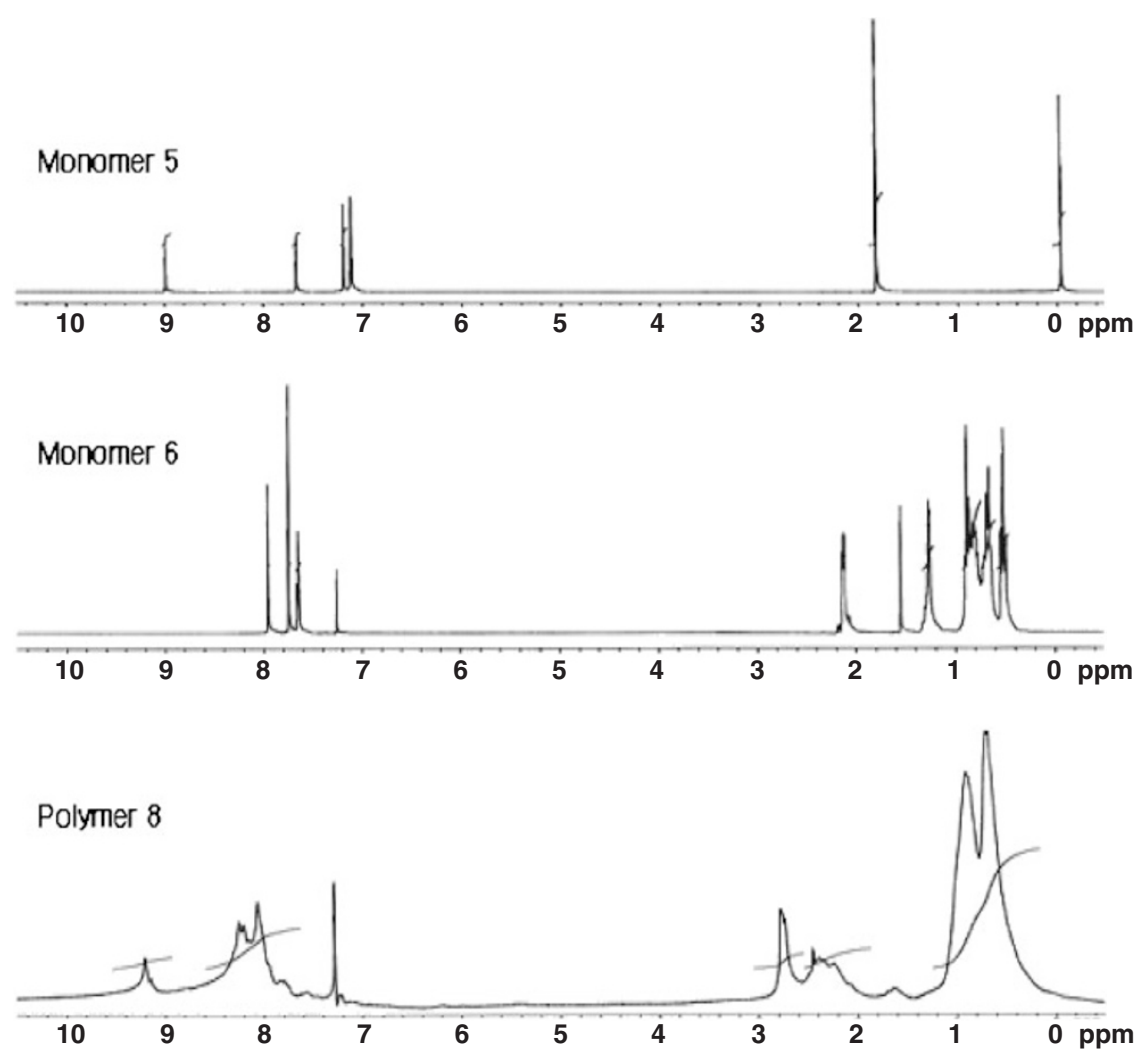

Figure 3. Comparison of ${ }^{1} \mathrm{H}$ NMR spectra of the polymer with those of monomeric compounds 5 and $\mathbf{6}$ in $\mathrm{CDCl}_{3}$.

ammonium chloride in DMSO and $50 \%$ aqueous $\mathrm{NaOH}$, to obtain 2,6-dibromo-4,4-bis(2-ethylhexyl)-4H-cyclopenta[def]phenanthrene (6), which, upon reaction with bis(pinacolato)diboron and catalytic amounts of $\mathrm{Pd}(\mathrm{dppf}) \mathrm{Cl}_{2}$ in $\mathrm{DMF}$ and potassium acetate, gave compound 7. Suzuki coupling ${ }^{16}$ of monomer 5 and 7 using $\mathrm{Pd}\left(\mathrm{PPh}_{3}\right)_{4}$ and $\mathrm{K}_{2} \mathrm{CO}_{3}$ gave the final copolymer product, PCPP-MSC (8), ${ }^{1} \mathrm{H}$ NMR of which was compared with compound $\mathbf{5}$ and $\mathbf{6}$ in Figure 3.

The resulting PCPP-MSC was soluble in organic solvents such as chloroform, tetrahydrofuran, dichloromethane, and chlorobenzene. The number-average molecular weight $\left(M_{\mathrm{n}}\right)$ and the weight-average molecular weight $\left(M_{\mathrm{w}}\right)$ of the PCPPMSC, determined by gel permeation chromatography (GPC) using THF as the eluent and polystyrene as the standard, was 10,400 and 17,700 , respectively, with a polydispersity index in the range of 1.7. The thermal properties of the polymer was determined by DSC and thermal gravimetric analysis under a nitrogen atmosphere at a heating rate of $10^{\circ} \mathrm{C} / \mathrm{min}$. PCPPMSC shows glass transition at $84^{\circ} \mathrm{C}$ and loses less than $5 \%$ of their weights on heating to $294^{\circ} \mathrm{C}$ (Figure 4). The high thermal stability of the resulting polymer prevents the deformation of the polymer morphology and degradation of the polymer lightemitting device by applied electric field of the LED.

\section{Optical Properties of Polymer}

As shown in Figure 5, PCPP-MSC showed an absorption spectrum with a maximum peak at $341 \mathrm{~nm}$ in chloroform. The film of the polymer was prepared by spin-casting from its chlorobenzene solution on a quartz substrate at room temperature, with the main absorption peak exhibited at $344 \mathrm{~nm}$, attributed to the $\pi-\pi^{*}$ transitions of the polymers. The polymer showed a different absorption spectrum side peak at $402 \mathrm{~nm}$ with the main bond at $344 \mathrm{~nm}$. Compared with the spectrum of PCPP, the difference in shape was caused by the methylsulfa- 


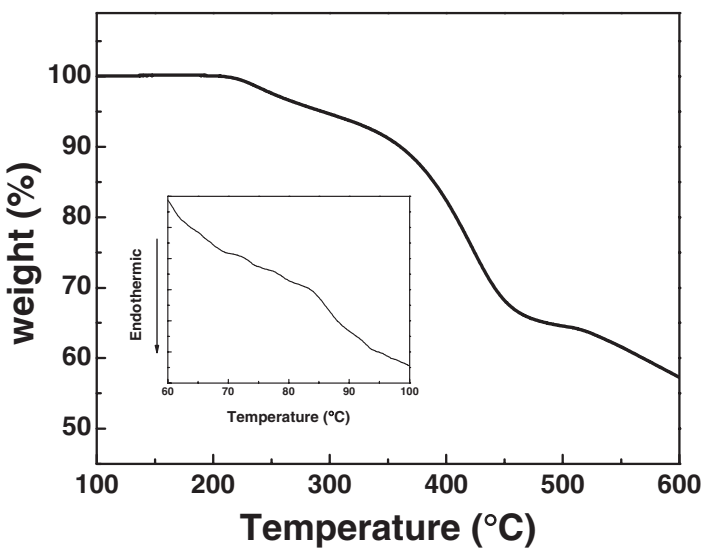

Figure 4. Thermogravimetric analysis of the PCPP-MSC under $\mathrm{N}_{2}$. Inner: Differential scanning calorimetry of the PCPP-MSC under $\mathrm{N}_{2}$.

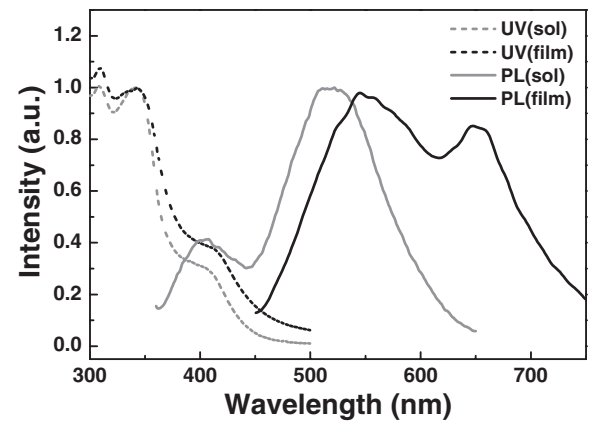

Figure 5. UV-vis absorption and photoluminescence emission spectra of PCPP-MSC in chloroform solution and in film.

nylmethylene units. The PL spectrum of the PCPP-MSC film showed a maximum at $545 \mathrm{~nm}$ and $649 \mathrm{~nm}$ with both the absorption and the emission spectra of the film red-shifted and broaden more than those in solution state, probably because of the increased intermolecular interactions due to methylsulfanylmethylene units between neighboring molecules in the film state. By this reason, the polymer exhibited the low absolute PL quantum yield of $0.12 \%$ in solution.

Figure 6 shows the PL spectra in chloroform at different concentrations for PCPP-MSC. At different concentrations, the polymer shows two PL emission peaks 404 and $522 \mathrm{~nm}$. The PL peak at $522 \mathrm{~nm}$ increased dramatically with increasing solution concentration, however, complete quenching of the host emission at $404 \mathrm{~nm}$ was observed at a concentration of $1 \times 10^{-5} \mathrm{~mol} / \mathrm{L}$, indicating complete aggregation between the cyclopentaphenanthrene segment and the methylsulfanylmethylene unit when an intermolecular interaction, by which the emission at around $400 \mathrm{~nm}$ responsible for the PCPP segment decreases very quickly with increasing copolymer concentration, takes place.

\section{Electrochemical Properties of Polymer}

The electrochemical properties of the polymer were determined from the band gap, estimated from the absorption edge, and the HOMO energy level, estimated using cyclic voltam-

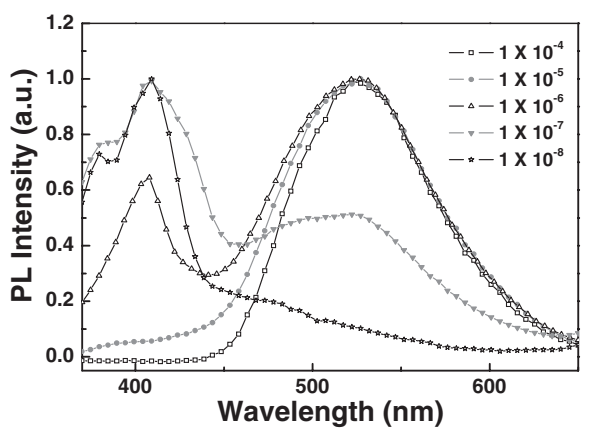

Figure 6. Photoluminescence spectra of PCPP-MSC in the chloroform solution at the concentration of $1 \times 10^{-4}$ to $1 \times 10^{-8} \mathrm{~mol} / \mathrm{L}$. The excitation wavelength is $340 \mathrm{~nm}$.

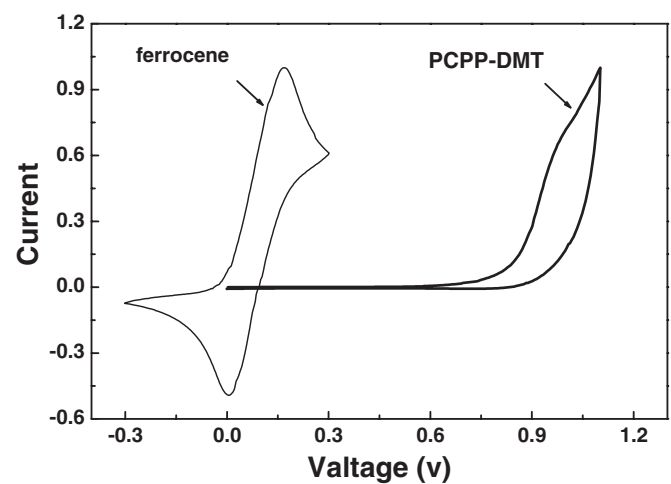

Figure 7. Cyclic voltammetry curvres of the PCPP-MSC in $0.1 \mathrm{M} \mathrm{Bu}_{4} \mathrm{NBF}_{4}$ acetonitrile solution at a scan rate of $100 \mathrm{mV} / \mathrm{s}$ at room temperature (vs. an Ag quasi-reference electrode).

metry (CV) (Figure 7). The cyclic voltammograms were recorded using a voltammetric analyzer at room temperature under nitrogen atmosphere. The measuring cell consisted of polymer-coated $\mathrm{Pt}$ as working electrode, $\mathrm{Ag} / \mathrm{AgCl}$ electrode as reference electrode, and platinum wire electrode as auxiliary electrode, supporting in $0.1 \mathrm{M}(n-\mathrm{Bu})_{4} \mathrm{NClO}_{4}$ in acetonitrile. The energy levels were calculated using the ferrocene value of $-4.8 \mathrm{eV}$ with respect to vacuum level, which is defined as zero. The oxidation potential is derived from the onset of electrochemical p-doping, and HOMO level was calculated according to the empirical formula $\left(\mathrm{E}_{\mathrm{HOMO}}=-\left(\left[\mathrm{E}_{\text {onset }}\right]_{\mathrm{ox}}+4.8\right)\right)(\mathrm{eV}) .{ }^{17}$ In the anodic scan, the onset of oxidation of PCPP-MSC occurred at $0.85 \mathrm{~V}$ ( $v s$. SCE), which corresponded to the ionization potential $\left(I_{\mathrm{p}}\right)$ value of $-5.65 \mathrm{eV}$. The absorption onset wavelength of PCPP-MSC was observed at $454 \mathrm{~nm}$ for the solid thin film, corresponding to band gap of $2.73 \mathrm{eV}$. The LUMO energy level of the present PCPP-MSC, calculated from the values of the band gap and HOMO energy level, was $-2.92 \mathrm{eV}$.

\section{Electroluminescent Properties of Polymer}

The electroluminescence (EL) spectrum of ITO/PEDOT/ PCPP-MSC/Ca:Al device is shown in Figure 8. This spectrum exhibited maximum peak at $661 \mathrm{~nm}$, corresponding to red light. The EL spectrum of the device using PCPP-MSC was very 


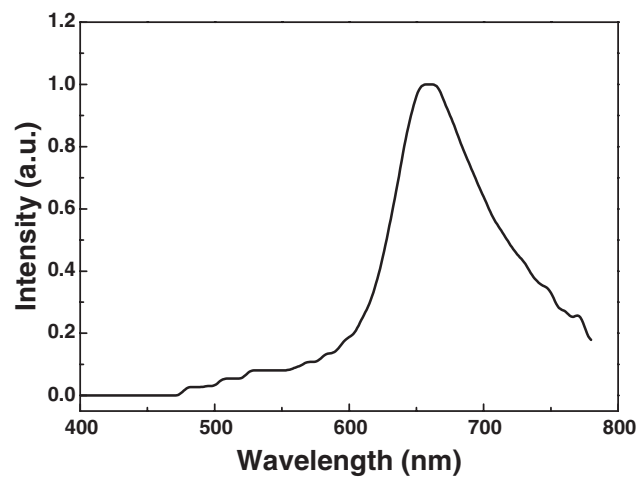

Figure 8. Electroluminescence spectrum of devices with the configuration of ITO/PEDOT:PSS/PCPP-MSC/Ca:AI.

different from the PL spectrum, whose maximum peak at $545 \mathrm{~nm}$ in the film disappeared in the EL spectrum, which exhibited the poor luminous efficiency of $0.001 \mathrm{~cd} / \mathrm{A}$ and the brightness of $0.434 \mathrm{~cd} / \mathrm{m}^{2}$. We can conclude that EL spectrum was red-shifted and the efficiency was decreased by aggregation between the PCPP segment and the methylsulfanylmethylene units.

\section{CONCLUSION}

In conclusion, we presented the synthesis of a new CPP derivative, MSC, with bis-methylsulfanyl-methylene unit, which was analyzed by using HRMS and NMR $(500 \mathrm{MHz})$, including COSY, HMQC, and HMBC, and was confirmed by $\mathrm{X}$-ray diffraction. This molecule was introduced in a new conjugated polymer, PCPP-MSC by the Suzuki coupling reaction. The bis-methylsulfanyl-methylene units affect a redshifted color change and increase the electron affinities of the polymer. The HOMO energy level of the polymer was $-5.65 \mathrm{eV}$, and the LUMO energy level was $-2.92 \mathrm{eV}$. The PCPP-MSC exhibited absorption spectra with maximum peak at $341 \mathrm{~nm}$ in chlorobenzene solution and at $344 \mathrm{~nm}$ in the solid film state. Its PL emission spectra in chloroform and in solid thin film showed maximum peaks at 404 and $522 \mathrm{~nm}$, and at 524 and $649 \mathrm{~nm}$, respectively. In a dilute chloroform solution, the PL peak at $522 \mathrm{~nm}$ increased dramatically and the PL peak at $404 \mathrm{~nm}$ was quenched completely with an increase in solution concentration. The complete aggregation between the cyclopentaphenanthrene segment and the methylsulfanylmethylene unit was generated by an intermolecular interaction.

Acknowledgment. This work supported by a Grant-in-Aid for the NCRC Program from MOST and KOSEF (No. R152006-022-01001-0), and the Ministry of Information \& Communications, Korea, under the Information Technology Research Center (ITRC).

Received: June 27, 2008 Accepted: October 30, 2008 Published: December 17, 2008

\section{REFERENCES}

1. a) J. R. Sheats, H. Antoniadis, M. Hueschen, W. Leonard, J. Miller, R. Moon, D. B. Roitman, and A. Stoching, Science, 273, 884 (1996). b) R. H. Friend, R. W. Gymer, A. B. Holmes, J. H. Burroughes, R. N. Marks, C. Taliani, D. D. C. Bradley, D. A. Santos, J. L. Bredas, M. Lőgdlund, and W. R. Salameck, Nature (London), 397, 121 (1999).

c) J. A. Mikroyannidis, K. M. Gibbons, A. P. Kulkarni, and S. A. Jenekhe, Macromolecules, 41, 663 (2008).

d) Y. Jin, J. Jee, K. Kim, J. Kim, S. Song, S. H. Park, K. Lee, and H. Suh, Polymer, 48, 1541 (2007).

e) W. Y. Lee, C. W. Chen, C. C. Chueh, C. C. Yang, and W. C. Chen, Polym. J., 40, 249 (2008).

2. a) M. Grell, D. D. C. Bradley, M. Inbasekaran, and E. P. Woo, $A d v$. Mater., 9, 798 (1997).

b) M. Ranger, D. Rondeau, and M. Leclerc, Macromolecules, 30, 7686 (1997).

c) Q. Pei and Y. Yang, J. Am. Chem. Soc., 118, 7416 (1996).

3. a) Y. Jin, J. Ju, J. Kim, S. Lee, J. Y. Kim, S. H. Park, S. M. Son, S. H. Jin, K. Lee, and H. Suh, Macromolecules, 36, 6970 (2003).

b) M. Vehse, B. Liu, L. Edman, G. C. Bazan, and A. J. Heeger, Adv. Mater., 16, 1001 (2004).

c) B. He, J. Li, Z. Bo, and Y. Huang, Polym. J., 39, 1345 (2007).

d) Y. Jin, J. Y. Kim, S. Song, Y. Xia, J. Kim, H. Y. Woo, K. Lee, and H. Suh, Polymer, 49, 467 (2008).

4. a) L.-H. Chan, Y.-D. Lee, and C.-T. Chen, Tetrahedron, 62, 9541 (2006).

b) N. C. Greenham, S. C. Moratti, D. D. C. Bradley, R. H. Friend, and A. B. Holmes, Nature, 365, 628 (1993).

5. a) J. Pei, X. Liu, W. Yu, Y. Lai, Y. Niu, and Y. Cao, Macromolecules, 35, 7274 (2002).

b) T. Virgili, D. G. Lidzey, and D. D. C. Bradley, Adv. Mater., 12, 58 (2000).

c) M. Yang, Q. Ling, M. Hiller, X. Fun, X. Liu, L. Wang, and W. Zhang, J. Polym. Sci., Part A: Polym. Chem., 38, 3405 (2000).

d) J. Morgado, F. Cacialli, R. Iqbal, S. C. Moratti, A. B. Holmes, G. Yahioglu, L. R. Milgrom, and R. H. Friend, J. Mater. Chem., 11, 278 (2001).

6. a) S. C. Ng, H. F. Lu, H. S. O. Chan, A. Fuji, T. Laga, and K. Yoshin, Adv. Mater., 12, 1122 (2000).

b) A. K. Agrawal and S. A. Jenekhe, Macromolecules, 24, 6806 (1991).

7. C. W. Tang, S. A. VanSlyke, and C. H. Chen, J. Appl. Phys., 65, 3610 (1989).

8. Q. Hou, Y. Xu, W. Yang, M. Yuan, J. Peng, and Y. Cao, J. Mater. Chem., 12, 2887 (2002).

9. I. S. Millard, Synth. Met., 111-112, 119 (2000).

10. a) S. Amriou, C. Wang, A. S. Batsanov, M. R. Bryce, D. F. Perepichka, E. Orti, R. Viruela, J. Vidal-Gancedo, and C. Rovira, Chem. Eur. J., 12, 3389 (2006).

b) K. Takagi, K. Saiki, K. Mori, Y. Yuki, and M. Suzuki, Polym. J., 39, 813 (2007).

11. a) R. Grisorio, P. Mastrorilli, G. Ciccarella, G. P. Suranna, and C. F. Nobile, Tetrahedron Lett., 49, 2078 (2008).

b) M. Heeney, C. Bailey, M. Giles, M. Shkunov, D. Sparrowe, S. Tierney, W. Zhang, and I. McCulloch, Macromolecules, 37, 5250 (2004).

12. a) H. Suh, Y. Jin, S. H. Park, D. Kim, J. Kim, C. Kim, J. Y. Kim, and K. Lee, Macromolecules, 38, 6285 (2005).

b) S. H. Park, Y. Jin, J. Y. Kim, S. H. Kim, J. Kim, H. Suh, and K. Lee, Adv. Funct. Mater., 17, 3063 (2007).

13. T. Horaguchi, R. Yamazaki, and T. Abe, Bull. Chem. Soc. Jpn., 53, 494 (1980).

14. K. Mitsuo, S. Hiroaki, and Y. Suehiko, J. Org. Chem., 53, 2093 (1988). 
15. Crystallographic data reported in this manuscript have been deposited with Cambridge Crystallographic Data Centre as supplementary publication nos. CCDC 680922.

16. N. Miyaura and A. Suzuki, Chem. Rev., 95, 2457 (1995).
17. a) S.-H. Jin, M.-Y. Kim, J. Y. Kim, K. Lee, and Y.-S. Gal, J. Am. Chem. Soc., 126, 2474 (2004).

b) D. M. Leeuw, M. M. J. Simenon, A. R. Brown, and R. E. F. Einerhand, Synth. Met., 87, 53 (1997). 